\title{
PHOSPHORYLATION OF CALCIUM/CALMODULIN-DEPENDENT PROTEIN KINASE II (CAMKII) AND EXTRACELLULAR REGULATED KINASE (ERK) IN STRIATUM MEDIATE NICOTINE DEPENDENCE IN BALB/C MICE
}

\author{
GOFARANA WILAR ${ }^{1,2 *}$, KOHJI FUKUNAGA²
}

1Department of Pharmacology and Clinical Pharmacy, Faculty of Pharmacy, Universitas Padjadjaran, Jl Raya Bandung-Sumedang KM 20,5 Desa Hegarmanah, Kecamatan Jatinangor, Sumedang, 45363 Indonesia, ${ }^{2}$ Department of Pharmacology, Graduate School of Pharmaceutical Sciences, Tohoku University, 6-3 Aoba, Aramaki, Aoba-ku, Sendai-shi, 980-8579 Japan

Email: g.wilar@unpad.ac.id

Received: 08 Aug 2021, Revised and Accepted: 15 Aug 2021

\section{ABSTRACT}

Objective: Nicotine is an active compound in tobacco and has a rewarding effect in the central nervous system (CNS), which may lead to dependence. Although nicotine dependence is elucidated by brain mechanisms, synaptic molecular substrates underlying the dependence remain unclear. We hypothesized that reward signaling is mediated by dopamine and glutamate receptors, in where calcium/calmodulin-dependent kinase II (CaMKII) and extracellular signal-regulated kinase (ERK) may mediate the synaptic signaling of dependence.

Methods: To investigate the roles of both CaMKII and ERK on nicotine dependence were assessed by conditioned place preference (CPP) methods followed by dissection. One day after conditioning, preference scores were measured to evaluate nicotine dependence. Mice were sacrificed and their striatum were dissected out for immunoblotting analyses of CaMKII and ERK phosphorylation.

Results: Nicotine-induced conditioned place preference as a symptom of nicotine dependence. CaMKII and ERK phosphorylation in striatum significantly increased along with the development of nicotine dependence.

Conclusion: We should next apply pharmacological strategies to manipulate CaMKII and ERK signaling. In particular, disruption of reconsolidation by disrupting CaMKII and ERK signaling may propose an attractive therapeutic approach to inhibit nicotine dependence.

Keywords: Nicotine dependence, CaMKII, ERK, Conditioned place preference, Preference score

(c) 2021 The Authors. Published by Innovare Academic Sciences Pvt Ltd.This is an open access article under the CC BYlicense (https://creativecommons.org/licenses/by/4.0/) DOI: https://dx.doi.org/10.22159/ijap.2021.v13s4.43825 Journal homepage: https://innovareacademics.in/journals/index.php/ijap

\section{INTRODUCTION}

Nicotine is an active compound and the main addictive material in tobacco products; nicotine dependence symptoms are characterized by compulsive use, craving, tolerance from continued use and withdrawal upon cessation [1]. Nicotine dependence is a chronic brain disorder and a worldwide primary public health issue [2]. Nicotine binds by main receptor nicotinic acetylcholine receptors (nAChRs), which are pentamers consisted of $\alpha 2, \alpha 4 \alpha 7, \alpha 10$, and $\beta 2$ $\beta 4$ subunits [3]. nAChRs are widely distributed in the central nervous system (CNS), including cortical and limbic regions. These receptors are critical for drug addiction through stimulation of synaptic activity in the hippocampus, amygdala, ventral tegmental area (VTA), and nucleus accumbens (NAc) and striatum region [4].

nAChRs are ligand-gated ion channels that were activated by the endogenous neurotransmitter acetylcholine (ACh) and the exogenous tertiary alkaloid nicotine [5]. Activation of nAChRs by nicotine stimulates calcium influx Calcium through nAChRs, especially via the alpha-bungarotoxin-sensitive alpha7-containing nAChRs, which is a very effective subtype of nAChRs on enhancing cytoplasmic calcium level [6]. Calcium entry through voltage-gated $\mathrm{Ca}^{2+}$ channels is critical in develop the Calcium/Calmodulin Protein Dependent Kinase (CaMKII) level [7]. On the other hand, Influx $\mathrm{Ca}^{2+}$ intracellular to result in activation and phosphorylation of PYK2, turn on the RAS through tyrosine kinase receptor and upstream the activity of extracellular regulated kinase 1/2 (ERK1/2) [8].

CaMKII is the most important $\mathrm{Ca}^{2+}$ sensors changing glutamatergic activation into synaptic plasticity during learning and memory formation, This cascade is pivotal for Long-Term Potentiation (LTP) as basis for morphological adaptations at the synapse during learning process [9]. ERK is a part of mitogen-activated protein kinases (MAPKs), affected in the modulation of many cellular processes, including cell proliferation, differentiation, growth, and death of cells. The previous study showed cocaine induces phosphorylation of ERK during dependence conditions [10]. Accumulating evidence supports
ERK-dependency in molecular adaptation, morphological plasticity, and behavioral performance such as nicotine like behaviour [11] Here, we performed the experiment to investigate the roles of CaMKII and ERK on nicotine dependence conditions. These observations led us to the discovery of the new mechanism of nicotine-induced conditioned place preference through CaMKII and ERK. Moreover, this research will provide a new approach to prevent nicotine dependence by inhibiting the phosphorylation of CaMKII and ERK.

\section{MATERIALS AND METHODS}

Materials

Male BALB/c mice aged $8 \mathrm{w}$ (20-30 g) were purchased from SLC (Hamamatsu, Japan), Mice were housed in a room with a 12/12-hour light/dark cycle (lights on at 09:00). Room conditions were temperature controlled at $22.0 \pm 2{ }^{\circ} \mathrm{C}$ with a relative humidity of $55 \% \pm 5 \%$. Mice had free access to food and water. All experimental animal procedures were approved by the Committee on Animal Experiments at Tohoku University, and studies were conducted following committee guidelines. Every effort was designated to minimize suffering and limit the number of animals used. Nicotine Hydrogen Tartrate was obtained from Sigma Aldrich. Phosphorylation of CaMKII antibody gift from Professor Kohji Fukunaga. Phosphorylation of ERK1/2 was purchased from cell signaling. Rabbit Secondary antibody was buyed from Abcam company.

The testing apparatus for the conditioned place preference consisted of three compartments measuring $12.7 \mathrm{cmx} 46.5 \mathrm{cmx} 12.7 \mathrm{~cm}$ (width $\mathrm{x}$ length $\mathrm{x}$ height) in size. The middle compartment was grey, called the neutral compartment. Two conditioning compartments differed in color and floor texture. Compartment A was white with a quadrangular sieve (mesh). The other compartment (B) was black with stainless steel floors. Each compartment was separated by two doors (fig. 1)

The immunoblotting analyses performed used Bio-rad apparatus, Protein separation by gel electrophoresis 1 . Load equal amounts of 
protein $(20 \mu \mathrm{g})$ into the wells of a mini $(8.6 \times 6.7 \mathrm{~cm})$ or midi $(13.3 \mathrm{x}$ $8.7 \mathrm{~cm}$ ) format SDS-PAGE gel, along with molecular weight markers. 2. Run the gel for $5 \mathrm{~min}$ at $50 \mathrm{~V}$. 3. Increase the voltage to $100-150 \mathrm{~V}$ to finish the run in about $1 \mathrm{~h}$.

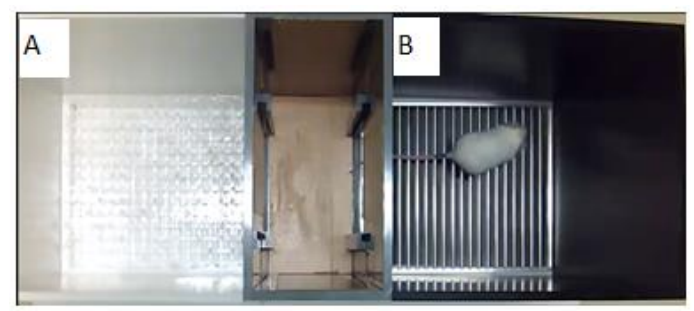

Fig. 1: Conditioned place preference box

\section{Nicotine-induced conditioned place preference}

Mice were divided into two groups, nicotine treatment group $n=6$ and vehicle treatment group $n=6$. Mice were first habituated to the CPP apparatus for five days; Acclimatization was performed for five days prior to pre-conditioning. It is designed to remove any environmental stress, including the weighing and testing rooms, CPP apparatus, and drug administration. Followed by a pre-conditioning test to determine the nicotine-paired compartment. Mice entered conditioning training for one month in which $0.5 \mathrm{mg} / \mathrm{kg}$ nicotine was administered intraperitoneally, followed by confinement in the designated compartment of CPP apparatus for 30 minute [12]. Four hours later, the same procedure was repeated, only this time saline was given instead of nicotine and the mouse was confined in the opposite of nicotine compartment. One day after conditioning, preference scores were measured three times to evaluate the nicotine dependence on preconditioning, $2 \mathrm{w}$ conditioning and $4 \mathrm{w}$ conditioning. Preference scores were calculated using this formula:

$$
\text { Preference Score }=\frac{\text { Sojourn time in nicotine compartment (s) }}{\text { Total time spent in all compartments (s) }}
$$

Preference ratio observed by counting the time spent in nicotine compartment and total time in all compartment using stopwatch

\section{Immunoblot analysis}

Mice were sacrificed immediately after preference score conditioning calculation, Striatum were dissected out form the brain mice. The tissues were stored in liquid nitrogen for temporary and then stored at $-80{ }^{\circ} \mathrm{C}$ until use. Western blot analysis was started as described. Striatum region samples were homogenized in $200 \mu \mathrm{l}$ homogenizing buffer containing $4 \mu \mathrm{m}$ ethylene glycol tetraacetic acid (EGTA), $50 \mu \mathrm{m}$ Tris-HCl (pH 7.4), $1 \mu \mathrm{m} \mathrm{Na} 3 \mathrm{VO}_{4}, 0.5 \%$ Triton X-100, $10 \mu \mathrm{m}$ EDTA,, $40 \mu \mathrm{m}$ sodium pyrophosphate, $50 \mu \mathrm{m} \mathrm{NaF}$, leupeptin $25 \mu \mathrm{g} \mathrm{ml}^{-1}$, pepstatin A $50 \mu \mathrm{g} \mathrm{ml}^{-1}$, trypsin inhibitor and $1 \mathrm{~mm}$ dithiothreitol (DTT), $100 \mu \mathrm{m}$ calyculin A $50 \mu \mathrm{gml}^{-1}$. 10 minutes centrifugation at $15000 \mathrm{r}$. p. m $4{ }^{\circ} \mathrm{C}$ was used to delete insoluble particle. After determining protein concentration in supernatants using Bradford's solution using a spectrophotometer, samples were boiled in $100^{\circ} \mathrm{C}$ incubator for 3 minutes in Laemmli buffer [13].

The samples containing equivalent amounts of protein were subjected to SDS-polyacrylamide gel electrophoresis (PAGE) at $500 \mathrm{~V}$ and 40 $\mathrm{mA}$. Proteins were transferred to an Immobilon polyvinylidene difluoride (PVDF) membrane (pore $=0.45 \mu \mathrm{m}$ ) (Millipore) for $2-\mathrm{h}$ at $70 \mathrm{~V}$. After blocking with TTBS solution (50 mm Tris-HCl, $\mathrm{pH} 7.5$, $150 \mathrm{~mm} \mathrm{NaCl}$ and $0.1 \%$ Tween 20 ) containing $5 \%$ of fat-free milk powder for 1-h at room temperature, membranes were incubated overnight at $4{ }^{\circ} \mathrm{C}$ with Anti-phospho-CaMKII (1:5000) [14]. Antiphospho-ERK (1:2000; Cell signaling lot number 9101) [15].

Pictures of the band were developed using an ECL immunoblotting detection system (Amersham Biosciences, Piscataway, NJ, USA) and were visualized on X-ray film (Fuji Film, Tokyo, Japan). Autoradiographic films were scanned for densitometry analysis (Lasergraphics, Irvine, CA, USA) and quantitative analyses were used Image Gauge version 3.41 (Fuji Film, Tokyo, Japan).

\section{RESULTS}

Nicotine administration generates nicotine-induced conditioned place preference as a symptom of nicotine dependence (fig. 2) which is characterized by elevation of the value of preference ratio.

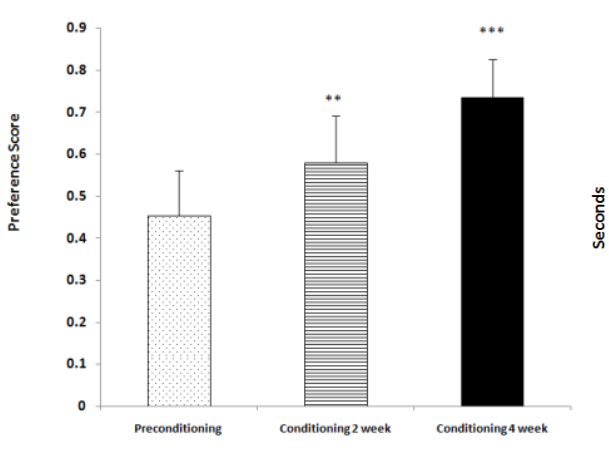

A

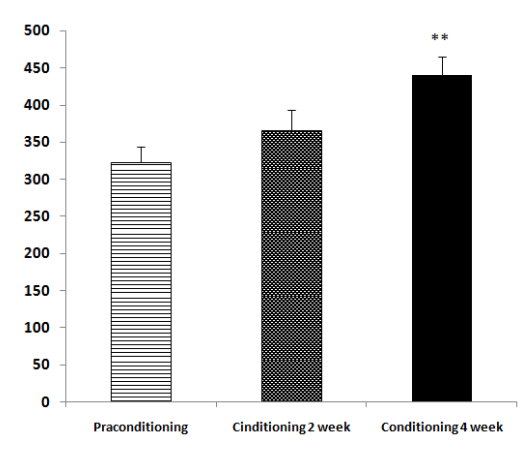

B

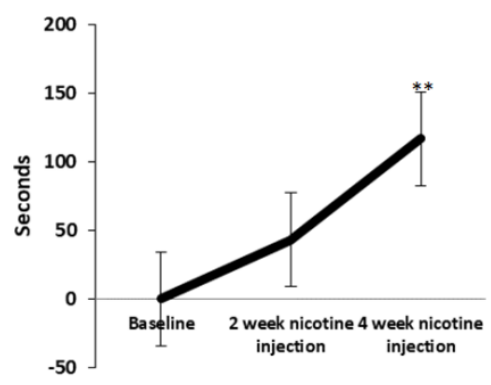

C

Fig. 2: Nicotine-induced conditioned place preference. A. Preference score of Nicotine dependence in $4 \mathrm{w}$ nicotine administration ( $\mathrm{n}=6)$. B. Time in Nicotine paired compartment after nicotine administration in 28 consecutive days $(n=6)$. C. $\Delta$ Time in Nicotine paired compartment (n=6). Data were presented as average \pm SEM and analyzed using one-way ANOVA followed by multiple comparisons between baseline condition and the results obtained $2 \mathrm{w}$ and $4 \mathrm{w}$ after nicotine administration post hoc Tukey tests. Significantly different was considered *p<0.05 were compared by preconditioning or baseline condition 
Nicotine administration induced nicotine dependence (fig. 2) which is characterized by increase of the value of preference ratio as a symptom nicotine dependence, preference ratio elevate 0.59 and 0.73 on $14 \mathrm{~d}$ and $28 \mathrm{~d}$ nicotine injection respectively compared to nicotine preadministration condition on normal mice 0.44 (fig. 2A) [16]. According to the preference ratio, the time spent on nicotine compartment significantly enhanced on $28 \mathrm{~d}$ of administration of nicotine even though the enhancement of time in nicotine compartment after 14 administration was not differently significant compared by preconditioning condition (fig. 2B). Moreover, our research shows if the change of time in nicotine compartment dramatically elevated more than 100 seconds in $28 \mathrm{~d}$ after nicotine administration (fig. 2C).
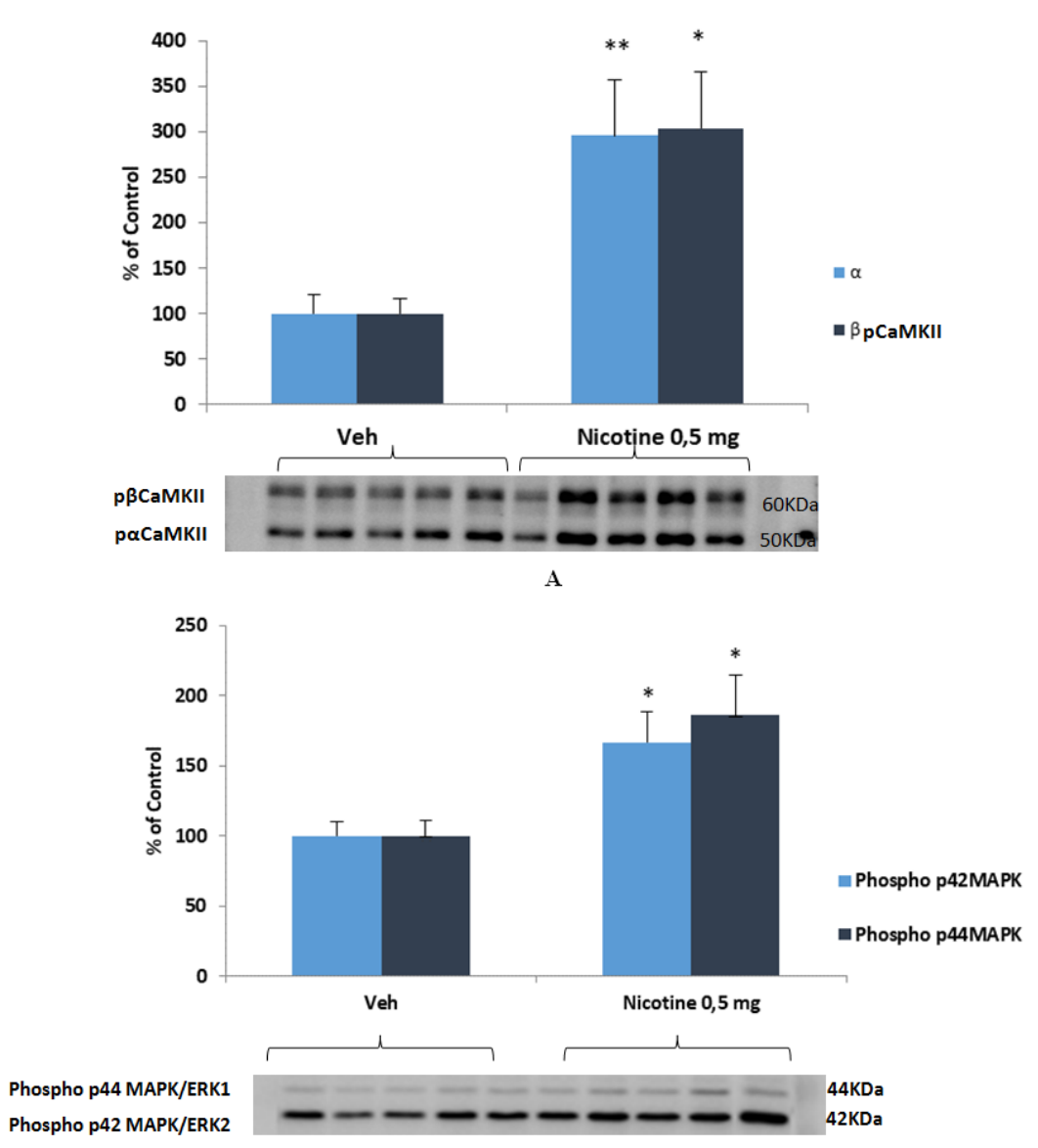

B

Fig. 3: The expression of phosphorylation CaMKII and ERK nicotine dependence on striatum brain region. A. Nicotine Induces Enhancement of CaMKII autophosphorylation in striatum $(n=5)$. B. Enhancement of ERK1/2 phosphorylation in striatum stimulated by nicotine administration $(n=5)$. Data were presented as average \pm SEM and analyzed using one-way ANOVA followed by multiple comparisons between vehicle condition and the results $4 \mathrm{w}$ after nicotine administration post hoc Tukey tests. Significantly different was considered ${ }^{*}$ p $<0.05$ were compared by vehicle group

Since two important mediators in memory formation, particularly in long-term potentiation of neurons, were recognized and mediated by CaMKII and ERK 1/2, we analyzed the concentration of phosphorylation of both protein using western blot methods. The nicotine dependence was associated with elevation of activity of phosphorylation CaMKII and ERK1/2 auto-phosphorylation on striatum of mice brains (fig. 3. A and 3 . B). The level of CaMKII phosphorylation markedly increased more than 2.5 fold compared to the level of CaMKII Phosphorylation on vehicle group 1 fold. In line with phosphorylation of CaMKII, Autophosphorylation of ERK 1/2 expression on striatum region also enhanced around $175 \%$, comparable to vehicle treatment group $100 \%$. ERK1/2 phosphorylation dramatically increases almost $75 \%$ if we compare to the vehicle group as an effect of nicotine administration for 28 consecutive days.

\section{DISCUSSION}

Nicotine is the neuroactive compound and addictive agent in tobacco, in the present study the administration of nicotine $0.5 \mathrm{mg} / \mathrm{kg}$ for 14 and $28 \mathrm{~d}$ is sufficient to induce dependence in mice. Nicotine successfully increases the preference ratio as a symptom of nicotine dependence on CPP methods, CPP is a familiar method to evaluate the rewarding effect of nicotine [17-20]. This protocol involves passive administration of the drug on one side of a conditioning apparatus, this method is substantially different from the drug selfadministration method [21]. In the drug self-administration method, repeated self-infusions are required to establish substance addiction behaviors. It is likely that repeated exposure affects receptor transduction mechanisms associated with tolerance and sensitization [21]. Moreover, CPP is the preferred method for rapid screening and can be used with many mouse strains with high sensitivity [22].

The prolonged nicotine exposure for $28 \mathrm{~d}$ results in neural adaptation following receptor desensitization and upregulation of nAChR $[23,24]$. chronic nicotine exposure selectively up-regulates the density of $\alpha 4 \beta 2$ to stimulates nicotine addiction in rats induction by nicotine [25]. Not different with $\alpha 4 \beta 2$ the $\alpha 7$ as homo-oligomer nAChRs also involved in nicotine dependence, approved by the high expression of $\alpha 7 \mathrm{nAChR}$ on striatum in a nicotine dependence rat model [26], on striatum nAChR bind with the nicotine and induce dependence. nAChRs is abundant in the family of ligand-gated ion channels that is expressed broadly throughout the central nervous 
system and peripheral nervous system, and in non-neuronal cells [27]. Calcium intracellular influx through nAChRs, particularly via the $\alpha$-bungarotoxin-sensitive $\alpha 7$-containing nAChRs, is a very effective way to raise cytoplasmic calcium concentration [6]. Calcium ions are one of the most important intracellular messengers known, and impacts almost every aspect of cellular life, including generating the proteins and their downstream effectors such as CaMKII and ERK1/2 [28].

Nicotine increases activity of CaMKII in the striatum region (fig. 3A) [29]. CaMKII in striatum may correlate by long-term potentiation on memory formation by nicotine and strengthen the memory concerned with convenient feeling during nicotine administration [13]. In addition, lack of CaMKII generates memory deterioration, the deficiency of CaMKII mice proposed to abolish the memory formation on remembering the nicotine-paired compartment and failed to evoke CPP [30,31]. Moreover, the ERK1/2 phosphorylation has been increased in striatum region nicotine dependence condition (fig. 3B)) due to calcium influx that was enhanced by stimulation of nAChR [32]. Influx $\mathrm{Ca}^{2+}$ intracellular to result in activation and phosphorylation of PYK2, in turn the RAS is activated through the tyrosine kinase receptor and upstream the activity of ERK1/2 [8]. Besides that, ERK1/2 activation through $\beta$ adrenoceptors plays a dual role in cell proliferation; it phosphorylates Stat 3 at Ser727 and regulates cell proliferation [33]. Accumulation of ERK1/2 autophosphorylation influences molecular adaptation, morphological plasticity, and behavioral performance such as nicotine like behaviour [11].

\section{CONCLUSION}

CaMKII and ERK phosphorylation significantly increased along with the development of nicotine dependence. We should next apply pharmacological strategies to manipulate CaMKII and ERK signaling. In particular, disruption of reconsolidation by disrupting CaMKII and ERK signaling may propose an attractive therapeutic approach to inhibit nicotine dependence.

\section{ACKNOWLEDGEMENT}

The authors would like to thank Assistance Professor Yasuharu Shinoda for technical assistance.

\section{FUNDING}

This research supported by Indonesia Endowment Fund to G. W and Kankenhi Japan to K. F.

\section{AUTHORS CONTRIBUTIONS}

All the authors contributed equally.

\section{CONFLICT OF INTERESTS}

Declared none

\section{REFERENCES}

1. Benowitz NL. Nicotine addiction. Prim Care. 1999;26(3):61131. doi: 10.1016/s0095-4543(05)70120-2, PMID 10436290

2. Henningfield JE, Miyasato K, Jasinski DR. Abuse liability and pharmacodynamic characteristics of intravenous and inhaled nicotine. J Pharmacol Exp Ther. 1985;234(1):1-12. PMID 4009494.

3. Changeux JP. Nicotine addiction and nicotinic receptors: lessons from genetically modified mice. Nat Rev Neurosci. 2010;11(6):389-401. doi: 10.1038/nrn2849, PMID 20485364.

4. Leslie FM, Mojica CY, Reynaga DD. Nicotinic receptors in addiction pathways. Mol Pharmacol. 2013;83(4):753-8. doi: 10.1124/mol.112.083659, PMID 23247824.

5. Albuquerque EX, Pereira EFR, Alkondon M, Rogers SW. Mammalian nicotinic acetylcholine receptors: from structure to function. Physiol Rev. 2009;89(1):73-120. doi: 10.1152/physrev.00015.2008, PMID 19126755.

6. Shen JX, Yakel JL. Nicotinic acetylcholine receptor-mediated calcium signaling in the nervous system. Acta Pharmacol Sin. 2009;30(6):673-80. doi: 10.1038/aps.2009.64, PMID 19448647.

7. Xiao RP, Cheng H, Lederer WJ, Suzuki T, Lakatta EG. Dual regulation of $\mathrm{Ca} 2+/$ calmodulin-dependent kinase II activity by membrane voltage and by calcium influx. Proc Natl Acad Sci
USA. 1994;91(20):9659-63. doi: 10.1073/pnas.91.20.9659, PMID 7937825.

8. Tahara S, Fukuda K, Kodama H, Kato T, Miyoshi S, Ogawa S. Potassium channel blocker activates extracellular signal-regulated kinases through Pyk2 and epidermal growth factor receptor in rat cardiomyocytes. J Am Coll Cardiol. 2001;38(5):1554-63. doi: 10.1016/s0735-1097(01)01558-3, PMID 11691539.

9. Sheng M, Kim MJ. Postsynaptic signaling and plasticity mechanisms. Science. 2002;298(5594):776-80. doi: 10.1126/science.1075333, PMID 12399578.

10. Valjent E, Corvol JC, Pages C, Besson MJ, Maldonado R, Caboche $\mathrm{J}$. Involvement of the extracellular signal-regulated kinase cascade for cocaine-rewarding properties. J Neurosci. 2000;20(23):8701-9. doi: 10.1523/JNEUROSCI.20-2308701.2000, PMID 11102476.

11. Chwang WB, O'Riordan KJ, Levenson JM, Sweatt JD. ERK/MAPK regulates hippocampal histone phosphorylation following contextual fear conditioning. Learn Mem. 2006;13(3):322-8. doi: 10.1101/lm.152906, PMID 16741283.

12. Benowitz NL, Porchet H, Sheiner L, Jacob P. Nicotine absorption and cardiovascular effects with smokeless tobacco use: comparison with cigarettes and nicotine gum. Clin Pharmacol Ther. 1988;44(1):23-8. doi: 10.1038/clpt.1988.107, PMID 3391001.

13. Wilar G, Shinoda Y, Sasaoka T, Fukunaga K. Crucial role of dopamine D2 receptor signaling in nicotine-induced conditioned place preference. Mol Neurobiol. 2019;56(12):7911-28. doi: 10.1007/s12035-019-1635-x, PMID 31129809.

14. Fukunaga $\mathrm{K}$, Goto S, Miyamoto E. Immunohistochemical localization of $\mathrm{Ca} 2+$ /calmodulin-dependent protein kinase II in rat brain and various tissues. J Neurochem. 1988;51(4):1070-8. doi: 10.1111/j.1471-4159.1988.tb03070.x, PMID 3047316.

15. Roux PP, Blenis J. ERK and p38 MAPK-activated protein kinases: a family of protein kinases with diverse biological functions. Microbiol Mol Biol Rev. 2004;68(2):320-44. doi: 10.1128/MMBR.68.2.320-344.2004, PMID 15187187.

16. Risinger FO, Oakes RA. Nicotine-induced conditioned place preference and conditioned place aversion in mice. Pharmacol Biochem Behav. 1995;51(2-3):457-61. doi: 10.1016/00913057(95)00007-j, PMID 7667368.

17. Carboni E, Vacca C. Conditioned place preference. Drugs Abus Neurol Rev Protoc. 2002;79:481-98.

18. Le Foll B, Goldberg SR. Nicotine induces conditioned place preferences over a large range of doses in rats.

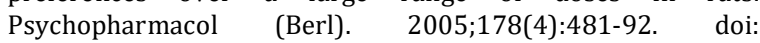
10.1007/s00213-004-2021-5, PMID 15765262.

19. Brielmaier JM, McDonald CG, Smith RF. Nicotine place preference in a biased conditioned place preference design. Pharmacol Biochem Behav. 2008;89(1):94-100. doi: 10.1016/j.pbb.2007.11.005, PMID 18086490.

20. Calcagnetti DJ, Schechter MD. Nicotine place preference using the biased method of conditioning. Prog Neuropsychopharmacol Biol Psychiatry. 1994;18(5):925-33. doi: 10.1016/0278-5846(94)90108-2, PMID 7972862.

21. Bardo MT, Bevins RA. Conditioned place preference: what does it add to our preclinical understanding of drug reward? Psychopharmacol (Berl). 2000;153(1):31-43. doi: $10.1007 / \mathrm{s} 002130000569$, PMID 11255927.

22. Cunningham CL, Dickinson SD, Grahame NJ, Okorn DM, McMullin CS. Genetic differences in cocaine-induced conditioned place preference in mice depend on conditioning trial duration. Psychopharmacol (Berl). 1999;146(1):73-80. doi: 10.1007/s002130051090, PMID 10485967.

23. Govind AP, Vezina P, Green WN. Nicotine-induced upregulation of nicotinic receptors: underlying mechanisms and relevance to nicotine addiction. Biochem Pharmacol. 2009;78(7):756-65. doi: 10.1016/j.bcp.2009.06.011, PMID 19540212.

24. Rogers SW, Gahring LC. Upregulation of nicotinic acetylcholine receptor alph4+beta2 through a ligand-independent PI3Kbeta mechanism that is enhanced by TNFalpha and the Jak2/p38MAPK pathways. PLOS ONE. 2015;10(11):e0143319. doi: 10.1371/journal.pone.0143319, PMID 26619345.

25. Nguyen HN, Rasmussen BA, Perry DC. Subtype-selective upregulation by chronic nicotine of high-affinity nicotinic receptors in rat brain demonstrated by receptor 
autoradiography. J Pharmacol Exp Ther. 2003;307(3):1090-7. doi: 10.1124/jpet.103.056408. PMID 14560040.

26. Nomikos GG, Schilström B, Hildebrand BE, Panagis G, Grenhoff J, Svensson TH. Role of alpha7 nicotinic receptors in nicotine dependence and implications for psychiatric illness. Behav Brain Res. 2000;113(1-2):97-103. doi: 10.1016/s01664328(00)00204-7, PMID 10942036.

27. Hurst R, Rollema H, Bertrand D. Nicotinic acetylcholine receptors: from basic science to therapeutics. Pharmacol Ther. 2013;137(1):22-54. doi: 10.1016/j.pharmthera.2012.08.012, PMID 22925690.

28. Gubbins EJ, Gopalakrishnan M, Li J. Alpha7 nAChR-mediated activation of MAP kinase pathways in PC12 cells. Brain Res. 2010;1328:1-11. doi: 10.1016/j.brainres.2010.02.083, PMID 20211606.

29. Jackson KJ, Muldoon PP, Walters C, Damaj MI. Neuronal calcium/calmodulin-dependent protein kinase II mediates nicotine reward in the conditioned place preference test in mice. Behav Pharmacol. 2016;27(1):50-6. doi: 10.1097/FBP.0000000000000189, PMID 26292186.
30. Picconi B, Gardoni F, Centonze D, Mauceri D, Cenci MA, Bernardi G, Calabresi P, Di Luca M. Abnormal Ca2+calmodulindependent protein kinase II function mediates synaptic and motor deficits in experimental parkinsonism. J Neurosci. 2004;24(23):5283-91. doi: 10.1523/JNEUROSCI.1224-04.2004, PMID 15190099.

31. Silva AJ, Paylor R, Wehner JM, Tonegawa S. Impaired spatial learning in alpha-calcium-calmodulin kinase II mutant mice. Science. 1992;257(5067):206-11. doi: 10.1126/science.1321493, PMID 1321493.

32. Nakayama H, Numakawa T, Ikeuchi T, Hatanaka H. Nicotineinduced phosphorylation of extracellular signal-regulated protein kinase and CREB in PC12h cells. J Neurochem. 2001;79(3):489-98. doi: 10.1046/j.1471-4159.2001.00602.x, PMID 11701752.

33. Chen RJ, Ho YS, Guo HR, Wang YJ. Rapid activation of Stat3 and ERK1/2 by nicotine modulates cell proliferation in human bladder cancer cells. Toxicol Sci. 2008;104(2):283-93. doi: 10.1093/toxsci/kfn086, PMID 18448488. 